\title{
REVIEW \\ Does early exercise attenuate muscle atrophy or bone loss after spinal cord injury?
}

\author{
MG Panisset ${ }^{1}$, MP Galea ${ }^{1}$ and D El-Ansary ${ }^{2}$
}

Objectives: To systematically identify and assess the evidence on the efficacy of exercise initiated early after traumatic spinal cord injury (SCl).

Methods: A comprehensive search (Any-2014) of eleven databases identified studies evaluating exercise interventions initiated within 12 weeks after $\mathrm{SCl}$ on muscle and bone loss in paralyzed limbs and comparing with standard care or immobilization. Two reviewers assessed methodological quality. One reviewer extracted data and critiqued results according to the Spinal Cord Injury Rehabilitation Evidence body of evidence framework.

Results: A total of 2811 titles were screened. Eleven studies were included: five randomized controlled trials, four cohort studies and two within-subject control studies. All provided level II evidence with a moderate risk of bias. Two studies found significant positive effects of high-load FES-resisted stance on physiological measures of muscle. Three reported positive effects of 3 months of Functional Electrical Stimulation (FES) on muscle size. Two studies found positive effects of 6-month body-weight supported treadmill training or FES on trabecular bone using $\mathrm{PQCT}$.

Conclusion: We found consistent evidence of positive effects of early exercise on muscle, possibly related to load intensity of the protocol. However, the heterogeneity of interventions and outcomes makes this determination speculative. Evidence for the effectiveness of early exercise on bone is scant and confined to measures of trabecular bone mineral density via pQCT. Transparent reporting of methods and variability of data, combined with standardization of valid and sensitive measures of muscle atrophy and bone loss, could facilitate future meta-analysis on this topic.

Spinal Cord (2016) 54, 84-92; doi:10.1038/sc.2015.150; published online 8 September 2015

\section{INTRODUCTION}

Although evidence supports the positive health effects of exercise interventions in chronic spinal cord injury (SCI), ${ }^{1-3}$ studies using animal models suggest that initiating exercise during a critical early period may optimize clinical outcomes. ${ }^{4}$ The literature reports that substantial atrophy of sub-lesional skeletal muscle takes place within the first 6-12 weeks post injury. ${ }^{5-7}$ Castro et al. ${ }^{7}$ reported that, at 6 weeks, thigh muscle cross-sectional area was on average 35\% less than that of size- and age-matched controls in the hamstrings and $31 \%$ less in the quadriceps.; at 11 weeks, the losses had increased to 41 and $38 \%$, respectively. Sadowsky et al. ${ }^{8}$ found a $36 \%$ mean increase in quadriceps muscle mass, with a concomitant $44 \%$ decrease in interand intramuscular fat, as well as an average 20-point increase in combined American Spinal Injury Association Impairment Scale (AIS) motor and sensory scores in 25 people with chronic SCI (AIS A-C) following functional electrical stimulation (FES) cycling ergometry (CE). A variety of interventions have been investigated to improve the muscle and bone of paralyzed limbs, with the aim of reducing secondary conditions such as fragility fractures and endocrinemetabolic disease. Some of these methods include FES-rowing, body-weight supported treadmill training (BWSTT), passive CE and robot-assisted ambulation. ${ }^{3}$
However, the clinical use of exercise during the acute period after SCI varies widely. Concerns about potential triggering of autonomic dysreflexia, ${ }^{9}$ unregulated hyperthermia ${ }^{10}$ or other effects of neurogenic shock may deter health professionals from utilizing exercise interventions in the acute phase. Although current clinical guidelines advocate regular exercise for chronic SCI, ${ }^{11}$ we are not aware of any recommendations regarding exercising early after SCI.

Promising therapies in rodent models have shown synergistic benefits of combining cellular or pharmacological therapies with physical exercise very early after injury. ${ }^{12,13}$ As rehabilitation frequency and duration has been acknowledged as a covariate for functional outcomes, ${ }^{14}$ we ought to be knowledgeable about the singular effects of potential adjunct exercise interventions, in order to accurately assess the relative benefits of experimental therapeutic agents in combination treatment protocols. Recent Phase I/IIa clinical studies involve administration of a therapy within $48 \mathrm{~h}$ and begin recording outcome measures as early as 1 week to 3 months. ${ }^{15}$

The aim of this study was to systematically review the evidence regarding the effects on bone and muscle tissue of exercise interventions involving paralyzed limbs in this early period after traumatic SCI.

${ }^{1}$ Department of Medicine, Royal Melbourne Hospital, The University of Melbourne, Parkville, Victoria, Australia and ${ }^{2}$ Department of Physiotherapy, Melbourne School of Health Sciences, The University of Melbourne, Parkville, Victoria, Australia

Correspondence: Professor MP Galea, Department of Medicine, Royal Melbourne Hospital, The University of Melbourne, Royal Park Campus, Building 21, 34-54 Poplar Road, Parkville 3052, Victoria, Australia.

E-mail: m.galea@unimelb.edu.au

Received 17 February 2015; revised 27 July 2015; accepted 29 July 2015; published online 8 September 2015 
Table 1 Eligibility criteria

\begin{tabular}{|c|c|c|}
\hline Criterion & Inclusion & Exclusion \\
\hline \multirow[t]{3}{*}{ Participants } & Traumatic $\mathrm{SCl}$ & Non-traumatic SCl \\
\hline & Adult $>18$ years of age & Animal studies \\
\hline & ASIA A, B or C & ASIA D \\
\hline Intervention & Exercise targeting paralyzed limbs initiated within 12 weeks after injury & $\begin{array}{l}\text { Volitional exercise of non-paralyzed body (for example, arm ergometry, } \\
\text { respiratory training) surgical, diagnostic, pharmaceutical }\end{array}$ \\
\hline Comparison & Standard care or immobilization & Outcome measures later than 6 months post-baseline \\
\hline Outcome measures & $\begin{array}{l}\text { Pertaining to neuromuscular or musculoskeletal tissues or function, } \\
\text { directly or indirectly (for example, power output) }\end{array}$ & $\begin{array}{l}\text { Psychological } \\
\text { Neurological } \\
\text { Cardiovascular }\end{array}$ \\
\hline Publication & $\begin{array}{l}\text { Any-2014 } \\
\text { Peer-reviewed journal } \\
\text { Abstract available in English }\end{array}$ & Conference abstracts \\
\hline
\end{tabular}

Abbreviations: ASIA, American Spinal Injury Association; SCI, spinal cord injury.

\section{MATERIALS AND METHODS} Eligibility criteria

The population intervention comparison outcome method was used to develop eligibility criteria for studies to include in the review. The population was confined to adult humans (age 18+) with acute traumatic SCI. We are aware of several potential interventions utilizing FES, passive ergometry or BWSTT, and new technologies are being developed rapidly. Therefore, the intervention criterion was purposefully broad and included any exercise intervention targeting the paralyzed limbs and initiated within 12 weeks post injury. Studies were sought, which compared early exercise intervention with standard care or immobilization, and reported outcomes measured within 6 months from baseline. The outcomes of interest were also exploratory; any valid measure reflecting muscle atrophy/hypertrophy or bone density/bone loss was eligible for inclusion.

The definition of 'acute' in reference to SCI is evolving. ${ }^{16}$ A recent review of exercise interventions defined 'acute SCI' as $<12$ months post injury, because after this point recovery of function has in large part plateaued. ${ }^{3}$ Although our choice of 12 weeks to define 'early' is somewhat arbitrary, evidence gleaned from this time frame would be relevant to translational studies of new therapeutics and also based on evidence that, although bone loss occurs immediately and gradually during the first 2 years post injury, thigh muscle atrophy occurs rapidly during the first 11 weeks and continues to decline up to 24 weeks. ${ }^{17}$ The National Spinal Cord Injury Statistical Center reports that the median length of stay in the USA over the past four decades for complete tetraplegics is 25 days in acute care followed by 97 days in rehabilitation. For those with incomplete injuries the figures are 14 days in acute and 41-58 days in rehabilitation, depending on level of the lesion. Although length of stay has been decreasing over time, 12 weeks can arguably be considered early for studies conducted in the $1980 \mathrm{~s}$ when the median rehabilitation stay was 120 days for complete tetraplegics. ${ }^{18}$

As we were interested in the effects of exercise on paralyzed limbs, we excluded studies with ASIA D participants. In that patient population, at least $50 \%$ of the muscles below the lesion have anti-gravity strength or better. The standard care exercise and activity levels of these individuals could be a significant confounder to the exercise interventions in question. All inclusion and exclusion criteria are presented in Table 1.

\section{Information resources}

A comprehensive search (Any- 2014) of eleven databases (Academic Search Complete, CINHAL, Cochrane, DOAJ, MEDLINE (OVID interface), Pedro, PhysEdIndex, PubMED, SCOPUS, Sports \& Rehab and SPORTSDiscus), a manual search of relevant clinical trial registers and the references of key papers and previous reviews and a free-text search of Google Scholar identified 2811 titles for screening.

\section{Scope}

As pioneering studies, describing the use of FES after SCI, were published as early as 1965 , we chose not to limit this search by date of publication. All English-language abstracts were screened, and articles written in languages other than English were not automatically excluded.

\section{Search strategy}

Development of the final search strategy was a highly iterative process. An initial search combining the terms 'acute spinal cord injury' and 'exercise' only retrieved three records. Eliminating 'acute' and combining 'spinal cord injury' and 'exercise' generated over 800 citations but failed to identify key articles known to the authors. The final search strategy employed an algorithm for each term, which was fine-tuned for each database, maximizing the use of available filters and qualifiers in order to minimize irrelevant records while still maintaining a broad and therefore comprehensive search (Appendix 1).

\section{Selection process}

The primary author eliminated duplicate records, studies without Englishlanguage abstracts and irrelevant studies by title. Two reviewers (MGP and MPG) independently evaluated the remaining abstracts for inclusion. Consultation with a third author (DE) provided resolution where the two reviewers were not in agreement. The selection process is illustrated in Figure 1.

\section{Appraisal of evidence}

The methodological quality of each paper was assessed using one of the two tools, according to the study design. Randomized controlled trials (RCTs) were appraised using the Physiotherapy Evidence Database (PEDro) tool. ${ }^{19}$ A systematic review on the assessment of non-randomized intervention studies identified the Downs and Black checklist as a robust tool for appraisal of non-randomized intervention studies. ${ }^{20,21}$ This scale has been customized for use in similar reviews. ${ }^{3,22}$ The criteria used in this review are included in Appendix 2. The primary author used a standardized data collection form to assess the risk of bias for each study. Uncertainties were resolved through discussion with the other two reviewers.

The primary author performed data extraction. Results are reported as mean difference between groups (percentage change from baseline) and 95\% confidence interval, where data were reported or able to be calculated. Confidence intervals were calculated using a confidence interval calculator available for download free from the PEDro website; http://www.pedro.org.au. ${ }^{23}$ Cohen's $d$ was calculated using a web-based effect size calculator. ${ }^{24}$ The level of evidence was determined according to the Spinal Cord Injury Rehabilitation Evidence (SCIRE) method. ${ }^{22}$ 


\section{RESULTS}

\section{Study selection}

Out of 2811 titles screened, 420 English-language abstracts were assessed, yielding 144 papers that required review via full-text. The majority of the exclusions thereafter occurred because the intervention

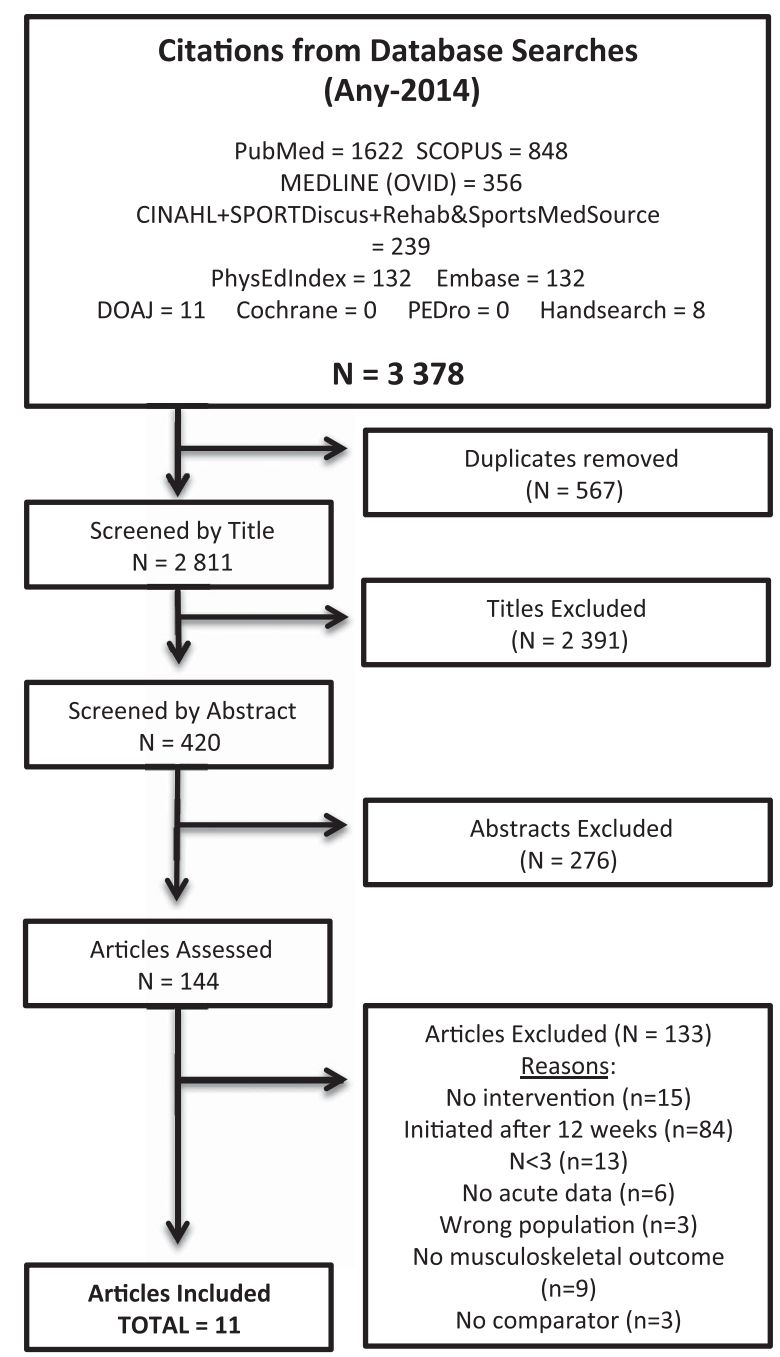

Figure 1 Flow chart of selection process. was initiated after 12 weeks post injury as indicated by a detailed review of each paper $(n=84)$. Five studies met the early intervention and outcome criteria, but two of them had no control group, ${ }^{25,26}$ one did not provide outcome measures prior to 1 year, ${ }^{27}$ one involved only participants with AIS C and D combined, ${ }^{28}$ and one study was reported via conference abstract only, and did not include point estimates or raw data for each group. ${ }^{29}$ Figure 1 illustrates the selection process. Eleven papers met all inclusion criteria.

\section{Study characteristics}

Study design, methodological quality scores and participant and intervention characteristics for each study are presented in Table 3. Our review included five RCTs, ${ }^{30-34}$ four cohort studies ${ }^{35-37}$ and two within-subject control studies. $^{38,39}$ All studies provided Level II evidence according to the SCIRE framework. All of the RCTs had a moderate-to-high risk of bias, with PEDro scores ranging from 3 to 5 out of 9. None of the RCTs utilized concealed allocation or intentto-treat analysis, nor did they blind subjects or therapists. Two used blinded assessors and achieved baseline comparability. ${ }^{30,34}$ All of them provided point estimates and variability, but the two smaller studies did not provide group estimates. ${ }^{32,34}$ Six prospective studies had an average Downs and Black score of 16.8 out of 27. Risk of bias was highest for external validity (28\%), selection bias (50\%), reporting of adverse events ( 0 studies) and providing actual $P$-values ( 2 studies). Higher scores indicated lower risk of bias in the reporting (71\%) and internal validity categories $(81 \%)$. The scores for each study can be found in the first column of Tables $2-4$.

\section{Interventions}

Four studies examined FES-CE. ${ }^{31,33,36,37}$ All FES-CE protocols were performed for $30 \mathrm{~min}, 3$ times per week. These studies used similar stimulation protocols but employed varying intensities, ranging from a mean power output of $2.2 \mathrm{~W}^{31}$ to $24.5 \mathrm{~W}^{33}$ after $12-13$-week training. Two studies continued the intervention duration to achieve a mean power output of $12.7 \pm 6.3 \mathrm{~W}$ after $4-9$ months $^{36}$ and a range of 11-35 W after 6 months. ${ }^{31}$ One study did not report power intensity. ${ }^{37}$ We categorized these interventions as having low-to-moderate load, because although $24.5 \mathrm{~W}$ is considerably more load than $2.2 \mathrm{~W}$, it is less than exercise intensity prescribed for a patient with congestive heart failure. ${ }^{40}$

One study ${ }^{41}$ examined the effects of BWSTT. Subjects exercised 3 times per week for 3-6 months. Because the body-weight support ranged from 20 to $80 \%$, this protocol was considered low load.

Table 2 Levels of evidence as used by SCIRE

\begin{tabular}{|c|c|c|}
\hline Level & Research design & Description \\
\hline Level 1 & $\mathrm{RCT}$ & RCT, PEDro score $\geqslant 6$. Includes within subjects comparison with randomized conditions and cross-over designs \\
\hline \multirow[t]{3}{*}{ Level 2} & RCT & RCT, PEDro score $<6$. \\
\hline & Prospective controlled trial & Prospective controlled trial (not randomized) \\
\hline & Cohort & Prospective longitudinal study using at least two similar groups with one exposed to a particular condition. \\
\hline Level 3 & Case control & A retrospective study comparing conditions, including historical controls \\
\hline \multirow[t]{2}{*}{ Level 4} & Pre-post & A prospective trial with a baseline measure, intervention, and a post-test using a single group of subjects. \\
\hline & Post-test & $\begin{array}{l}\text { A prospective post-test with two or more groups-intervention, then post-test (no pre-test or baseline measurement) using a single } \\
\text { group of subjects. }\end{array}$ \\
\hline \multirow[t]{4}{*}{ Level 5} & Case series & A retrospective study usually collecting variables from a chart review. \\
\hline & Observational & Study using cross-sectional analysis to interpret relations. \\
\hline & Clinical consensus & Expert opinion without explicit critical appraisal, or based on physiology, biomechanics or 'first principles' \\
\hline & Case report & Pre-post or case series involving one subject \\
\hline
\end{tabular}

Abbreviation: RCT, randomized controlled trial. 
Table 3 Characteristics of included studies

\begin{tabular}{|c|c|c|c|c|c|c|c|}
\hline $\begin{array}{l}\text { First author (Downs and } \\
\text { Black or PEDro score) }\end{array}$ & Study design & Groups & $\mathrm{n}$ & $\begin{array}{c}\text { ASIA percentage } \\
\text { complete (A:B:C:D) }\end{array}$ & $\begin{array}{c}\text { Neurological level } \\
\text { (percentage } \\
\text { cervical) }\end{array}$ & $\begin{array}{c}\text { Time since } \\
\text { injury (weeks) }\end{array}$ & Intervention (muscle groups) \\
\hline \multirow[t]{2}{*}{ Arija-Blazquez $(P=5)$} & \multirow[t]{2}{*}{$\mathrm{RCT}$} & Intervention & 5 & $100 \%(5: 0: 0: 0)$ & $0 \%$ & $5.5 \pm 1.1$ & FES (Quads) \\
\hline & & Control & 3 & $100 \%(3: 0: 0: 0)$ & $0 \%$ & $5.8 \pm 1.7$ & Sham FES \\
\hline \multirow[t]{3}{*}{ Baldi $(P=4)$} & \multirow[t]{3}{*}{$\mathrm{RCT}$} & Intervention (High) & 9 & $100 \%(N R)$ & $56 \%$ & $9.2 \pm 3.3$ & FES-CE (Quads, HS and Gluteals) \\
\hline & & Intervention (low) & 8 & $100 \%(N R)$ & $38 \%$ & $8.3 \pm 3.2$ & FES-IC (Quads, HS and Gluteals) \\
\hline & & Control & 9 & $100 \%(N R)$ & $11 \%$ & $8.4 \pm 3.5$ & SC \\
\hline \multirow[t]{2}{*}{ Clark $(D \& B=15)$} & \multirow[t]{2}{*}{ Non-concurrent cohort } & Intervention & 23 & $100 \%(N R)$ & $57 \%$ & 3 & FES (Quads and DF) \\
\hline & & Control & 10 & $80 \%(N R)$ & $20 \%$ & 3 & SC \\
\hline \multirow[t]{2}{*}{ Crameri $(P=3 ; D \& B=16)$} & \multirow[t]{2}{*}{$\mathrm{RCT}$} & Intervention & 4 & $100 \%(N R)$ & $0 \%$ & $2-4$ & FES (Quads and HS) \\
\hline & & Control & 2 & $100 \%(N R)$ & $0 \%$ & $2-4$ & $\mathrm{SC}$ \\
\hline \multirow[t]{3}{*}{ de Bruin $(D \& B=14)$} & \multirow[t]{3}{*}{ Cohort } & Intervention (high) & 4 & $0 \%(0: 0: 3: 1)$ & $75 \%$ & $2-4$ & BWSTT \\
\hline & & Intervention (low) & 5 & $100 \%(4: 1: 0: 0)$ & $0 \%$ & $1-3$ & SS \\
\hline & & Control: SCl & 4 & $75 \%(1: 2: 1: 0)$ & $75 \%$ & NR & SS \\
\hline \multirow[t]{3}{*}{ Demchak $(P=5)$} & \multirow[t]{3}{*}{$\mathrm{RCT}$} & Intervention & 5 & $100 \%(4: 1: 0: 0)$ & $60 \%$ & $4-6$ & FES-CE (Quads, HS and Gluteals) \\
\hline & & Control - SCl & 5 & $100 \%(4: 1: 0: 0)$ & $40 \%$ & $4-6$ & SC \\
\hline & & Control: uninjured & 5 & NA & NA & NA & NA \\
\hline \multirow[t]{4}{*}{ Dudley-Javoroski $(D \& B=19)$} & \multirow[t]{2}{*}{ Within-subject control } & Intervention (high) & 7 & $100 \%(7: 0: 0: 0)$ & $14 \%$ & $<12(n=2)$ & FES-RS (Quads) \\
\hline & & Opposite leg (low) & 5 & $100 \%(4: 1: 0: 0)$ & $0 \%$ & $<12(n=1)$ & SS \\
\hline & \multirow[t]{2}{*}{ Cohort } & Control: SCl & 16 & $100 \%(14: 2: 0: 0)$ & $6 \%$ & & SC \\
\hline & & Control: uninjured & 14 & NA & NA & NA & NA \\
\hline \multirow[t]{2}{*}{ Eser $(D \& B=14)$} & \multirow[t]{2}{*}{ Cohort } & Intervention & 19 & $100 \%(N R)$ & $42 \%$ & $2.6 \pm .9$ & FES-CE (Quads, HS and Gluteals) \\
\hline & & control & 19 & $100 \%(N R)$ & $42 \%$ & $4.5 \pm 3.3$ & SS \\
\hline \multirow[t]{2}{*}{ Groah $(P=4)$} & \multirow[t]{2}{*}{$\mathrm{RCT}$} & Intervention & 16 & $100 \%(15: 1: 0: 0)$ & $56 \%$ & $<12$ & FES-AG (Quads) \\
\hline & & control & 10 & $100 \%(8: 2: 0: 0)$ & $30 \%$ & $<12$ & $\mathrm{SC}$ \\
\hline \multirow[t]{2}{*}{ Lai $(D \& B=16)$} & \multirow[t]{2}{*}{ Matched cohort } & Intervention & 12 & $100 \%(12: 0: 0: 0)$ & $42 \%$ & $4-7$ & FES-CE (Quads and HS) \\
\hline & & Control & 12 & $100 \%(12: 0: 0: 0)$ & $42 \%$ & $4-7$ & $\mathrm{SC}$ \\
\hline \multirow[t]{2}{*}{ Shields $(D \& B=20)$} & \multirow[t]{2}{*}{ Within-subject control } & Intervention & 7 & $100 \%(7: 0: 0: 0)$ & $29 \%$ & $<6$ & FES-RS (Soleus) \\
\hline & & Opposite leg & & & & & SS \\
\hline
\end{tabular}

Abbreviations: ASIA, American Spinal Injury Association; BWSST, body-weight supported treadmill training; CE, cycle ergometry; D\&B, Downs and Black Score; DF, dorsiflexors; FES, Functional Electrical Stimulation; HS, hamstrings; NA, not available; NR, not reported; P, PEDro score; Quads, quadriceps; RCT, randomized controlled trial; RS, resisted stance; SC, standard care;

$\mathrm{SCl}$, spinal cord injury; SS, supported standing.

Two studies ${ }^{38,39}$ employed functional electrical stimulation in resisted stance (FES-RS) to provide loading to the muscles and bone of one lower limb, up to $1.5 \times$ body weight, using the participant's untrained limb as the comparator. These studies were considered high-load interventions. FES was applied to the quadriceps in one study ( $15 \mathrm{~min}, 3-5$ times per week), ${ }^{38}$ whereas, the soleus muscle was targeted in the other ( $30 \mathrm{~min}, 4-5$ times per week). ${ }^{39}$ Both studies also examined the effects of passive standing in the untrained limbs of these participants for a within-subject control comparison.

Finally, four studies ${ }^{30-32,34,35}$ administered FES to lower limb muscles without resistance or load (FES-IC) and one employed FES to extend the knee, lifting the leg against gravity (FES-AG). ${ }^{34}$ These we classified as low-load interventions. The majority of these studies stimulated the quadriceps muscles either alone or in combination with the hamstrings. In one study, the quadriceps were stimulated along with the ankle dorsiflexors. ${ }^{35}$ Protocol frequency for FES-IC was consistent across these studies at 5 times per week. In the study by Clark et al., ${ }^{24}$ compliance with the protocol was weakest (61\%). Although others ranged from 68 to $83 \%$ compliance, 6 of the studies did not report on compliance levels.

\section{Adverse events}

Out of 16 studies, including the 5 early intervention studies that were excluded due to lack of comparators, only nine studies reported monitoring for adverse events. All of these reported that no adverse events were associated with early exercise. Where monitoring was not reported, authors were contacted for further information, resulting in an additional two studies confirming an absence of adverse events. The total combined number of participants who safely participated in exercise within 12 weeks post injury in these sixteen studies included 28 who performed FES-CE, 11 who performed BWSTT and 43 who underwent FES-IC. Given that this information is not reported for 5 studies, the risk of reporting bias should be noted. Likewise, one must always consider that publishing bias favors positive results. ${ }^{42}$

\section{Muscle function and body composition}

Table 4 summarizes the results of the interventions for all muscle outcomes. Two studies found significant positive effects on physiological measures of muscle contractions with 6 months of high-load FES-resisted stance ${ }^{38,39}$ using a within-subject control design. Three studies $^{30,31,33}$ found evidence of positive effects on muscle and body composition after 12-14 weeks of exercise intervention. Moderate intensity FES-CE ${ }^{33}$ resulted in significant increases in muscle power after only 5 weeks. Muscle biopsy showed that this protocol was accompanied by significant increases in muscle fiber cross-sectional area (CSA) after 13 weeks, compared with controls. A low-intensity FES-CE protocol showed a significant increase in lean body mass after 6 months. ${ }^{31}$ Results from unloaded FES protocols were inconsistent. One study found unloaded FES performed an average of $4 \mathrm{~h}$ per week over 14 weeks, led to an increase in thigh muscle CSA, visualized by 
Table 4 Summary of muscle outcomes in order of methodological quality

\begin{tabular}{|c|c|c|c|c|c|c|c|c|}
\hline $\begin{array}{l}\text { First author, year } \\
\text { (Downs and Black } \\
\text { or PEDro score) }\end{array}$ & $\begin{array}{l}\text { Intervention (mus- } \\
\text { cles) }\end{array}$ & Work load & $\begin{array}{c}\text { Frequency } \\
\text { per } \\
\text { week } \times \text { min }\end{array}$ & $\begin{array}{l}\text { Duration } \\
\text { (compliance) }\end{array}$ & $\begin{array}{l}\text { Outcome mea- } \\
\text { sure }\end{array}$ & $\begin{array}{c}\text { Between-group } \\
\text { tests }\end{array}$ & $\begin{array}{c}\text { Estimated mean } \\
\text { difference } \\
\text { (confidence intervals) }\end{array}$ & $\begin{array}{l}\text { Effect Size } \\
\text { (Cohen's d) }\end{array}$ \\
\hline \multirow[t]{2}{*}{$\begin{array}{l}\text { Demchak, } 2005 \\
(P=5)\end{array}$} & $\begin{array}{l}\text { FES-CE (Quads, } \\
\text { HS and Gluteals) }\end{array}$ & $\begin{array}{l}\text { Mod } \\
(24.5 \pm 3.2 W)\end{array}$ & $3 \times 30$ & $\begin{array}{l}13 \text { weeks } \\
\text { (NR) }\end{array}$ & $\begin{array}{l}\text { Muscle fiber } \\
\text { CSA }\end{array}$ & $\begin{array}{c}\uparrow \text { FES-CE (+63\%) } \\
\text { Control }(-72 \%)\end{array}$ & $\wedge$ & $\begin{array}{l}\text { Very large (3.2) } \\
\text { Non-normalized PIV } \\
\text { CSA }\end{array}$ \\
\hline & & & & & $\begin{array}{l}\text { Muscle fiber } \\
\text { type }\end{array}$ & \# & $\wedge$ & $\wedge$ \\
\hline \multirow[t]{2}{*}{$\begin{array}{l}\text { Arija-Blazquez, } \\
2014(P=5)\end{array}$} & FES-IC (Quads) & Unloaded & $5 \times 47$ & $\begin{array}{l}14 \text { weeks } \\
\text { (NR) }\end{array}$ & $\begin{array}{l}\text { Average CSA of } \\
\text { quads (MRI) }\end{array}$ & $\uparrow$ & $24.8 \%(13-36.7 \%)$ & Very large (3.6) \\
\hline & & & & & $\begin{array}{l}\text { Max CSA of } \\
\text { quads (MRI) }\end{array}$ & $\uparrow$ & $30.6 \%(7.2-54 \%)$ & Large (2.2) \\
\hline \multirow[t]{5}{*}{$\begin{array}{l}\text { Baldi, } 1998 \\
(P=4)\end{array}$} & $\begin{array}{l}\text { FES-CE (Quads, } \\
\text { HS and Gluteals) }\end{array}$ & $\begin{array}{l}\text { Low } \\
(2.2 \pm 1.1 \mathrm{~W})\end{array}$ & $3 \times 30$ & $\begin{array}{l}3 \text { months } \\
\text { (NR) }\end{array}$ & $\begin{array}{l}\text { LBM: gluteal } \\
\text { (DXA) }\end{array}$ & $\uparrow$ & $\diamond$ & $\wedge$ \\
\hline & & & & & LBM: LL (DXA) & $\uparrow$ & $\diamond$ & $\wedge$ \\
\hline & & & & $\begin{array}{l}6 \text { months } \\
\text { (NR) }\end{array}$ & $\begin{array}{l}\text { LBM: Gluteal } \\
\text { (DXA) }\end{array}$ & $\uparrow$ & $34.5 \%(31-38 \%)$ & Very large (9.3) \\
\hline & & & & & LBM - LL (DXA) & $\uparrow+$ & $30.7 \%(26-35.5 \%)$ & Very large (6.4) \\
\hline & FES-IC & Unloaded & $3 \times 30$ & $\begin{array}{l}3 \text { and } \\
6 \text { months } \\
\text { (NR) }\end{array}$ & LBM: LL (DXA) & \# & $\diamond$ & $\wedge$ \\
\hline \multirow[t]{3}{*}{$\begin{array}{l}\text { Shields, } 2006 \\
(D \& B=20)\end{array}$} & FES-RS (Soleus) & $\begin{array}{l}\text { High }(150 \% \\
\text { BW) }\end{array}$ & $5 \times 30$ & $\begin{array}{l}6 \text { months } \\
(83 \%)\end{array}$ & $\begin{array}{l}\text { Peak torque } \\
\text { contractions } \\
\# 1-5\end{array}$ & $\uparrow$ & $34 \%$ & $\wedge$ \\
\hline & & & & & Fatigue index & $\uparrow$ & $\diamond$ & $\wedge$ \\
\hline & & & & & Torque rise time & $\uparrow$ & $\bullet$ & $\wedge$ \\
\hline \multirow[t]{2}{*}{$\begin{array}{l}\text { Dudley-Javoroski, } \\
2012(D \& B=19)\end{array}$} & FES-RS (Quads) & $\begin{array}{l}\text { High }(150 \% \\
\text { BW) }\end{array}$ & $3-5 \times 15$ & $\begin{array}{l}6 \text { months } \\
(68 \%)\end{array}$ & Quads force & $\uparrow^{* *}$ & $\wedge$ & $\wedge$ \\
\hline & & & & & Fatique index & $\uparrow$ & $\wedge$ & $\wedge$ \\
\hline \multirow[t]{2}{*}{$\begin{array}{l}\text { Crameri, } 2000 \\
(P=3 ; D \& B=16)\end{array}$} & $\begin{array}{l}\text { FES-IC (Quads } \\
\text { and HS) }\end{array}$ & Unloaded & $5 \times 60$ & 4 months & $\begin{array}{l}\text { Muscle fiber } \\
\text { CSA }\end{array}$ & \# & $\wedge$ & $\wedge$ \\
\hline & & & & & $\begin{array}{l}\text { Muscle fiber } \\
\text { type changes }\end{array}$ & \# & $\wedge$ & $\wedge$ \\
\hline
\end{tabular}

Abbreviations: AG, against gravity; BMD, bone mineral density; BW, body weight; CSA, cross-sectional area; D\&B, Downs and Black Score; DF, dorsiflexors; DXA, dual x-ray absorptiomentry; FES, functional electrical stimulation; CE, cycle ergomentry; HS, hamstrings; IC, isometric contractions; LBM, lean body mass; Mod, moderate; NR, not reported; $P$, PEDro score; pQCT, peripheral quantitative-computed tomography; Quads, quadriceps; RS, resisted stance. $\uparrow$ significant benefit compared with controls, +significant difference compared with low-intensity exercise group quantitative-computed tomography; Quads, quadriceps; RS, resisted stance. $\uparrow$ significant benefit compared with controls, + significant differ
$(P<0.05) ;{ }^{* *}$ significant difference between groups $(P<0.01)$; \# no significant difference; $\wedge$ unable to calculate; $\bullet$ data in graphs only.

MRI, which was associated with healthier baseline blood glucose levels and improved carbohydrate metabolism. ${ }^{30}$ However, two other studies found no significant differences in muscle outcomes after 4-9 months, although these studies were of poorer methodological quality. ${ }^{31,32}$

\section{Outcomes of bone measurements}

Table 5 summarizes the results of the interventions for all bone outcomes. Eight studies examined the effects of early exercise on bone tissue. Five measured bone mineral density with dual x-ray absorptiometry (DXA) and found no significant differences. Two studies measured cortical bone changes at the mid-shaft of the tibia, via CT and pQCT, and found no effect. Two studies measured the effect of BWSTT $^{41}$ or FES-RS ${ }^{39}$ on trabecular bone of the tibia using pQCT, and both found a significant positive effect after 6 months of intervention.

\section{DISCUSSION}

The aim of this review was to identify and synthesize all information published to date regarding the efficacy of early exercise interventions targeting the paralyzed limbs, initiated within the first 12 weeks after traumatic SCI. An exhaustive search found 16 papers that met these criteria; however, five were thereafter excluded for not meeting the criterion for reporting of comparison data.

Eleven out of those sixteen studies monitored adverse events and found none. This is consistent with reports from the SCI Locomotor Trial, a multisite RCT that found no increase in adverse events with BWSTT, initiated an average of 4.5 weeks post SCI (AIS B-D), compared with conventional physical therapy. ${ }^{43}$ However, there remains considerable risk of reporting and publication bias on this important matter.

Overall, the body of evidence presented here would be considered level II evidence based on study design, according to the SCIRE methodology. However, there was a moderate risk of bias in all studies, primarily for selection bias and external validity. The methodological quality of the reviewed studies was fair, but the majority of the studies had only a small sample size, a common problem when studying this population. ${ }^{16}$ Ideally, a meta-analysis would be able to combine multiple small studies to build a more robust base of evidence. However, only half of the studies reported sufficient data to allow confidence intervals and effect sizes to be calculated. Furthermore, the variety of interventions, with varying intensities (0-24 W), durations (4 weeks-3 years) and outcome measures precluded a meta-analysis in this review. 
Table 5 Summary of bone outcomes in order of methodological quality

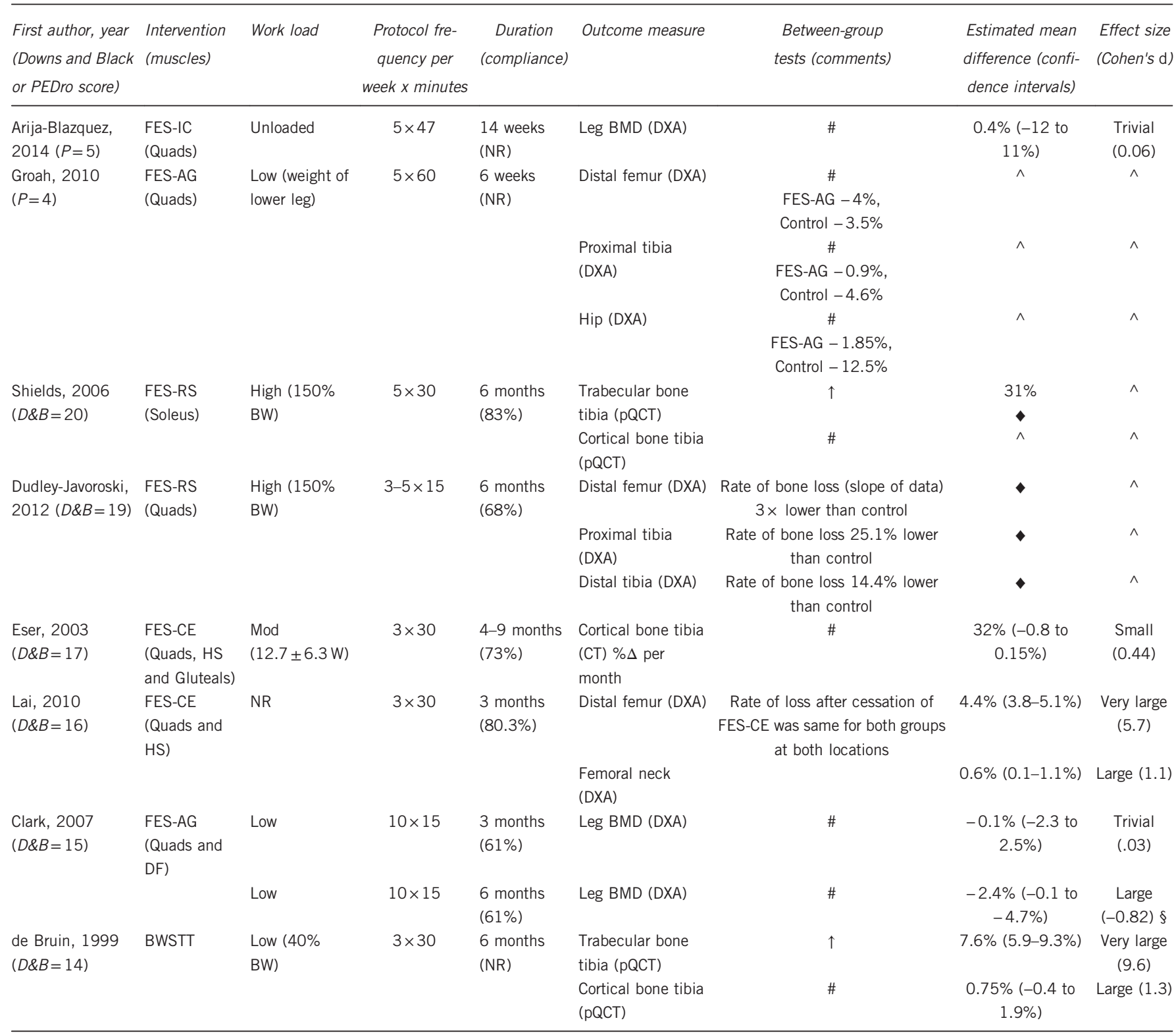

Abbreviations: AG, against gravity; BMD, bone mineral density; BW, body weight; BWSTT, body-weight supported treadmill training; D\&B, Downs and Black Score; DF, dorsiflexors; DXA, dual x-ray absorptiomentry; FES, functional electrical stimulation; CE, cycle ergomentry; CT, computed tomography; HS, hamstrings; IC, isometric contractions; Mod, moderate; NR, not reported; $P$, PEDro score; $\mathrm{pQCT}$, peripheral quantitative-computed tomography; Quads, quadriceps; RS, resisted stance. $\uparrow$ significant benefit compared with controls, +significant difference compared with low-intensity exercise group $(P<0.05)$; **significant difference between groups $(P<0.01)$; \#no significant difference; ^unable to calculate; data in graphs only; §opposite of expected.

The results from our review appear nonetheless to support literature, indicating that paralyzed muscle tissue can hypertrophy with FES within a 3 -month time frame. ${ }^{44}$ Some large effect sizes were reported in muscle outcomes at 3-month follow-up points. The magnitude of muscle hypertrophy may be related to either the amount of resistance and/or the length of intervention, but given the diversity of outcome measures such comparisons remain speculative. One included study showed that improvements in muscle tissue correlated with improved metabolic indicators. ${ }^{30}$ This is consistent with studies of similar interventions in the chronic SCI population. ${ }^{8,45}$ Further research is warranted to determine the clinical relevance of gaining or maintaining muscle tissue in the early period post SCI.
In contrast to the results seen with muscle outcomes, there was minimal evidence in this review of any exercise attenuating bone loss. This may be expected, as bone loss in acute SCI occurs at a much slower rate of $3-4 \%$ per month in the first half year ${ }^{46}$ when compared with the rate of muscle atrophy, which is as much as $40 \%$ in the first 11 weeks. ${ }^{7}$ There is an increased possibility of type II error in studies using DXA to measure changes in BMD, as pQCT measures of trabecular bone have been shown to be the most sensitive predictor of fractures in SCI. ${ }^{47}$ In particular, two studies that used whole lower limb BMD (DXA) $)^{30,35}$ may have been unable to detect an effect because others have shown smaller effect sizes distal to the site of FES. ${ }^{34,37}$ Edwards et al ${ }^{48}$ observed that a decline of $2 \%$ in BMD after acute SCI correlated to a 7\% loss in CT-based finite element modeling 
of femoral strength; thus, even a seemingly small change in DXA values could be clinically meaningful. A recent retrospective crosssectional study determined that the use of FES was associated with a lower prevalence of osteoporosis in chronic SCI. ${ }^{49}$

\section{Limitations}

Limitations of this review are in part due to the nature of the studies that were included. Small sample size, poor reporting and risk of bias were common. This review was purposefully broad in its scope; however, the resulting heterogeneity of interventions and outcomes precluded a synthesis of the evidence. Although every effort was made for quality control, one author undertook data extraction.

\section{CONCLUSION}

We found some consistent level II evidence of a positive effect of early exercise on muscle tissue within the first 3-6 months post SCI, possibly related to load and intensity of the exercise protocol. However, the heterogeneity of interventions and outcome measures used makes this determination speculative.

Evidence for the effectiveness of these interventions on bone is scant and confined to measures of trabecular bone mineral density via pQCT in two studies. ${ }^{39,41}$ This may be a type II error, resulting from insensitive measures. In particular, the use of DXA measures of BMD, which was common in these studies, has been shown to be inferior to pQCT measures of trabecular bone in the SCI population. ${ }^{47}$

Further work is needed to identify valid and sensitive outcome measures of muscle atrophy and bone loss, which could be standardized for use in clinical trials in order to facilitate future meta-analysis, as has been done with other outcome domains with the Comprehensive International Classification of Functioning, Disability and Health (ICF) Core Set. ${ }^{50}$ In order to make use of such measures, future studies must also maintain scientific rigor, utilize transparent reporting of methods and include confidence intervals and effect estimates. Only then can the data from small studies be utilized and built upon.

\section{CONFLICT OF INTEREST}

The authors declare no conflict of interest.

1 Cadotte DW, Fehlings MG. Spinal cord injury: a systematic review of current treatment options. Clin Orthop Relat Res 2011; 469: 732-741.

2 Dolbow DR, Gorgey AS, Daniels JA, Adler RA, Moore JR, Gater DR Jr. The effects of spinal cord injury and exercise on bone mass: a literature review. NeuroRehabilitation 2011; 29: 261-269.

3 Hicks AL, Martin Ginis KA, Pelletier CA, Ditor DS, Foulon B, Wolfe DL. The effects of exercise training on physical capacity, strength, body composition and functional performance among adults with spinal cord injury: a systematic review. Spinal Cord 2011; 49: 1103-1127.

4 Battistuzzo CR, Callister RJ, Callister R, Galea MP. A systematic review of exercise training to promote locomotor recovery in animal models of spinal cord injury. J Neurotrauma 2012; 29: 1600-1613.

5 Gorgey AS, Dudley GA. Skeletal muscle atrophy and increased intramuscular fat after incomplete spinal cord injury. Spinal Cord 2007; 45: 304-309.

6 de Groot PC, Bleeker MW, van Kuppevelt DH, van der Woude LH, Hopman MT. Rapid and extensive arterial adaptations after spinal cord injury. Arch Phys Med Rehabil 2006; 87: 688-696.

7 Castro MJ, Apple DF Jr., Hillegass EA, Dudley GA. Influence of complete spinal cord injury on skeletal muscle cross-sectional area within the first 6 months of injury. Eur J Appl Physiol Occup Physiol 1999; 80: 373-378.

8 Sadowsky CL, Hammond ER, Strohl AB, Commean PK, Eby SA, Damiano DL et al. Lower extremity functional electrical stimulation cycling promotes physical and functional recovery in chronic spinal cord injury. J Spinal Cord Med 2013; 36: 623-631.

9 Krassioukov AV, Furlan JC, Fehlings MG. Autonomic dysreflexia in acute spinal cord injury: an under-recognized clinical entity. J Neurotrauma 2003; 20: 707-716.

10 Jacobs PL, Nash MS. Exercise recommendations for individuals with spinal cord injury. Sports Med 2004; 34: 727-751.
11 Ginis KA, Hicks AL, Latimer AE, Warburton DE, Bourne C, Ditor DS et al. The development of evidence-informed physical activity guidelines for adults with spinal cord injury. Spinal Cord 2011; 49: 1088-1096.

12 Garcia-Alias G, Fawcett JW. Training and anti-CSPG combination therapy for spinal cord injury. Exp Neurol 2012; 235: 26-32.

13 Weishaupt N, Li S, Di Pardo A, Sipione S, Fouad K. Synergistic effects of BDNF and rehabilitative training on recovery after cervical spinal cord injury. Behav Brain Res 2013; 239: 31-42.

14 Lammertse D, Tuszynski MH, Steeves JD, Curt A, Fawcett JW, Rask C et al. Guidelines for the conduct of clinical trials for spinal cord injury as developed by the ICCP panel: clinical trial design. Spinal Cord 2007; 45: 232-242.

15 Kamiya K, Koda M, Furuya T, Kato K, Takahashi H, Sakuma T et al. Neuroprotective therapy with granulocyte colony-stimulating factor in acute spinal cord injury: a comparison with high-dose methylprednisolone as a historical control. Eur Spine $J$ 2015; 24: 963-967.

16 Fawcett JW, Curt A, Steeves JD, Coleman WP, Tuszynski MH, Lammertse D et al. Guidelines for the conduct of clinical trials for spinal cord injury as developed by the ICCP panel: spontaneous recovery after spinal cord injury and statistical power needed for therapeutic clinical trials. Spinal Cord 2007; 45: 190-205.

17 Castro MJ, Apple DF Jr., Staron RS, Campos GE, Dudley GA. Influence of complete spinal cord injury on skeletal muscle within 6 mo of injury. J Appl Physiol 1999; 86: 350-358.

18 NSCIS Center Annual Statistical Report-Complete Public Version. 2014.

19 Maher CG, Sherrington C, Herbert RD, Moseley AM, Elkins M. Reliability of the PEDro scale for rating quality of randomized controlled trials. Phys Ther 2003; 83: 713-721.

20 Downs SH, Black N. The feasibility of creating a checklist for the assessment of the methodological quality both of randomised and non-randomised studies of health care interventions. J Epidemiol Community Health 1998; 52: 377-384.

21 Saunders LD, Soomro GM, Buckingham J, Jamtvedt G, Raina P. Assessing the methodological quality of nonrandomized intervention studies. West J Nurs Res 2003; 25: 223-237.

22 Eng JJ, Teasell R, Miller WC, Wolfe DL, Townson AF, Aubut JA et al. Spinal cord injury rehabilitation evidence: methods of the SCIRE systematic review. Top Spinal Cord Rehabil 2007; 13: 1-10.

23 Herbert R. Confidence Interval Calculator 2013. Available at http://www.pedro.org.au/ english/downloads/confidence-interval-calculator/2013 (accessed on 25 June 2015).

24 Ellis PD. Effect Size Calculators. 2009. Available at http://www.polyu.edu.hk/mm/ effectsizefaqs/calculator/calculator.html.

25 Nymark J, DeForge D, Barbeau H, Badour M, Bercovitch S, Tomas J et al. Body weight support treadmill gait training in the subacute recovery phase of incomplete spinal cord injury. J Neurol Rehabil 1998; 12: 119-138.

26 Rischbieth HM, Clark J, Jelbart M, Strayer J, Donohoe S, Marshall R. 7th Annual Conference of the International Functional Electrical Stimulation Society Failure of Surface Low Level Functional Electrical Stimulation (LLFES) to Demonstrably Influence Body Composition over a 2 Year Period following Acute Spinal Cord Injury (SCI). 2002.

27 Shields RK, Dudley-Javoroski S, Oza PD. Low-frequency H-reflex depression in trained human soleus after spinal cord injury. Neurosci Lett 2011; 499: 88-92.

28 Postans NJ, Hasler JP, Granat MH, Maxwell DJ. Functional electric stimulation to augment partial weight-bearing supported treadmill training for patients with acute incomplete spinal cord injury: a pilot study. Arch Phys Med Rehabil 2004; 85: 604-610.

29 Nery M, Middleton J, Crameri R, Clifton-Bligh P. Bone mineral density and functional electrical stimulation in acute spinal cord injury. Bone 2005; 36: S382-S382.

30 Arija-Blazquez A, Ceruelo-Abajo S, Diaz-Merino MS, Godino-Duran JA, Martinez-Dhier $\mathrm{L}$, Martin JL et al. Effects of electromyostimulation on muscle and bone in men with acute traumatic spinal cord injury: a randomized clinical trial. J Spinal Cord Med 2014; 37: 299-309.

31 Baldi JC, Jackson RD, Moraille R, Mysiw WJ. Muscle atrophy is prevented in patients with acute spinal cord injury using functional electrical stimulation. Spinal Cord 1998; 36: 463-469.

32 Crameri RM, Weston AR, Rutkowski S, Middleton JW, Davis GM, Sutton JR. Effects of electrical stimulation leg training during the acute phase of spinal cord injury: a pilot study. Eur J Appl Physiol 2000; 83: 409-415.

33 Demchak TJ, Linderman JK, Mysiw WJ, Jackson R, Suun J, Devor ST. Effects of functional electric stimulation cycle ergometry training on lower limb musculature in acute sci individuals. J Sports Sci Med 2005; 4: 263-271.

34 Groah SL, Lichy AM, Libin AV, Ljungberg I. Intensive electrical stimulation attenuates femoral bone loss in acute spinal cord injury. PM R 2010; 2: 1080-1087.

35 Clark JM, Jelbart M, Rischbieth H, Strayer J, Chatterton B, Schultz C et al. Physiological effects of lower extremity functional electrical stimulation in early spinal cord injury: lack of efficacy to prevent bone loss. Spinal Cord 2007; 45: 78-85.

36 Eser P, de Bruin ED, Telley I, Lechner HE, Knecht H, Stussi E. Effect of electrical stimulation-induced cycling on bone mineral density in spinal cord-injured patients. Eur J Clin Invest 2003; 33: 412-419.

37 Lai CH, Chang WH, Chan WP, Peng CW, Shen LK, Chen JJ et al. Effects of functional electrical stimulation cycling exercise on bone mineral density loss in the early stages of spinal cord injury. J Rehabil Med 2010; 42: 150-154.

38 Dudley-Javoroski S, Saha PK, Liang G, Li C, Gao Z, Shields RK. High dose compressive loads attenuate bone mineral loss in humans with spinal cord injury. Osteoporos Int 2012; 23: 2335-2346.

39 Shields RK, Dudley-Javoroski S. Musculoskeletal plasticity after acute spinal cord injury: effects of long-term neuromuscular electrical stimulation training. J Neurophysiol 2006; 95: 2380-2390. 
40 Francis GS, Goldsmith SR, Ziesche S, Nakajima H, Cohn JN. Relative attenuation of sympathetic drive during exercise in patients with congestive heart failure. J Am Coll Cardiol 1985; 5: 832-839.

41 de Bruin ED, Frey-Rindova P, Herzog RE, Dietz V, Dambacher MA, Stussi E. Changes of tibia bone properties after spinal cord injury: effects of early intervention. Arch Phys Med Rehabil 1999; 80: 214-220.

42 Altman DG, Bland JM. Absence of evidence is not evidence of absence. BMJ 1995; 311: 485.

43 Dobkin B, Apple D, Barbeau H, Basso M, Behrman A, Deforge D et al. Weight-supported treadmill vs over-ground training for walking after acute incomplete $\mathrm{SCl}$. Neurology 2006; 66: 484-493.

44 Griffin L, Decker MJ, Hwang JY, Wang B, Kitchen K, Ding Z et al. Functional electrical stimulation cycling improves body composition, metabolic and neural factors in persons with spinal cord injury. J Electromyogr Kinesiol 2009; 19: 614-622.

45 Jeon JY, Weiss CB, Steadward RD, Ryan E, Burnham RS, Bell G et al. Improved glucose tolerance and insulin sensitivity after electrical stimulation-assisted cycling in people with spinal cord injury. Spinal Cord 2002; 40: 110-117.

46 Edwards WB, Schnitzer TJ, Troy KL. Bone mineral and stiffness loss at the distal femur and proximal tibia in acute spinal cord injury. Osteoporos Int 2014; 25: 1005-1015.

47 Eser P, Frotzler A, Zehnder Y, Denoth J. Fracture threshold in the femur and tibia of people with spinal cord injury as determined by peripheral quantitative computed tomography. Arch Phys Med Rehabil 2005; 86: 498-504.

48 Edwards WB, Schnitzer TJ, Troy KL. Reduction in proximal femoral strength in patients with acute spinal cord injury. J Bone Miner Res 2014; 29: 2074-2079.

49 Hammond ER, Metcalf HM, McDonald JW, Sadowsky CL. Bone mass in individuals with chronic spinal cord injury: associations with activity-based therapy, neurologic and functional status, a retrospective study. Arch Phys Med Rehabil 2014; 95 2342-2349.

50 Kirchberger I, Cieza A, Biering-Sorensen F, Baumberger M, Charlifue S, Post MW et al. ICF core sets for individuals with spinal cord injury in the early post-acute context. Spinal Cord 2010; 48: 297-304.

\section{APPENDIX 1}

Search strategy

\begin{tabular}{|c|c|c|}
\hline Construct & Database & Search terms \\
\hline Acute $\mathrm{SCl}$ & All & $\begin{array}{l}\text { Spinal Cord Injuries } \\
\text { OR Parapleg* } \\
\text { OR tetrapleg* } \\
\text { OR quadripleg* } \\
\text { AND Humans } \\
\text { AND Adult }\end{array}$ \\
\hline Exercise & All & $\begin{array}{l}\text { Rehabilitation OR } \\
\text { exercise OR activity } \\
\text { OR electric* OR sti- } \\
\text { mulat* OR FES OR } \\
\text { resist* OR train* OR } \\
\text { cycling OR rowing OR } \\
\text { ergometry OR contin- } \\
\text { uous passive motion } \\
\text { OR continuous pas- } \\
\text { sive movement OR } \\
\text { gait }\end{array}$ \\
\hline Exercise & $\begin{array}{l}\text { CINAHL } \\
\text { SPORTS-DISCUS } \\
\text { Sports \& Rehab } \\
\text { Academic Search } \\
\text { Complete }\end{array}$ & $\begin{array}{l}\text { Rehabilitation OR } \\
\text { exercise OR activity } \\
\text { OR electric*OR sti- } \\
\text { mulat* OR resist*OR } \\
\text { train*OR cycling OR } \\
\text { rowing }\end{array}$ \\
\hline
\end{tabular}

Musculo-skeletal

Outcome
Qualifiers

AND NOT (TOPIC

=chronic OR com-

munity OR wheel-

chair OR athlete) AND NOT (Topic $=$ resp* OR pulm* OR bladder OR bowel OR urin* OR sexual OR ejacula*)

Narrow by SubjectMajor:

Rehabilitation, Elec-

tric stimulation, Electrical stimulation functional, Physical therapy, Therapeutic exercise, Gait training, Physical Activity, Exercise, Rehabilitation patients

\begin{tabular}{|c|c|c|c|}
\hline & Medline & physiology OR & \\
\hline & PubMed & rehabilitation) & \\
\hline & DOAJ & & \\
\hline Musculo-skeletal & CINAHL & & Narrow by Subject- \\
\hline outcome & SPORTS-DISCUS & & Major: \\
\hline & Sports \& Rehab & & Outcome assessment, \\
\hline & Academic Search & & Treatment outcomes, \\
\hline & Complete & & Recovery, Exercise \\
\hline & & & physiology, Muscle \\
\hline & & & (skeletal), Spasticity, \\
\hline & & & Instrument validation \\
\hline Musculo-skeletal & SCOPUS & Title, Abstract, Key- & Limit to Subject \\
\hline outcome & & word: atrophy OR & Areas: \\
\hline & & muscle OR muscular & MEDI \\
\hline & & OR body composition & OR HEAL \\
\hline & & OR fat-free mass OR & OR NEUR \\
\hline & & bone OR osteop* OR & OR NURS \\
\hline & & strength OR power & \\
\hline & & OR cross-sectional & \\
\hline & & area & \\
\hline
\end{tabular}

\section{APPENDIX 2}

Modified Downs and Black tool

\section{Reporting}

1. Is the aim, hypothesis or objectives of the study clearly stated?

2. Are the outcomes to be measured clearly described?

3. Are the characteristics of the participants adequately reported?

4. Are the interventions of interest clearly described?

5. Is the distribution of principal confounders in each group of participants adequately reported?

6. Are the main findings of the study clearly reported?

7. Does the report indicate the extent of random variability in the data for the main outcomes?

8. Were adverse events monitored and adequately reported?

9. Are drop-outs and participants lost to follow-up reported and adequately described?

10. Have actual probability values been reported (e.g. 0.035 rather than $<0.05)$ for the main outcomes, except where the probability value is less than 0.001 ?

\section{External validity}

11. Were the subjects asked to participate in the study representative of the entire population from which they were recruited?

12. Were those subjects who were prepared to participate representative of the entire population from which they were recruited?

13. Were the staff, places and facilities where the patients were treated, representative of the treatment the majority of patients receive?

\section{Internal validity—bias}

14. Were measurement protocols of the main outcome measures standardized and automated or performed by blind assessors?

15. If any of the results of the study were based on 'data dredging', was this made clear? 
16. Were the follow-up measures taken across the same time period or, if not, were the analyses adjusted?

17. Were appropriate statistics employed?

18. Was compliance reliable $(>85 \%)$

19. Were the outcome measures reliable and valid?

\section{Internal validity-confounding (selection bias)}

20. Were all participants recruited from the same population?

21. Were all participants recruited over the same period of time?

22. Were participants randomized to intervention groups?
23. Was the randomized intervention assignment concealed from both patients and health-care staff until recruitment was complete and irrevocable?

24. Were confounders stratified or adjusted for in the main analyses?

25. Were participant drop-outs or losses to follow-up taken into account in the analysis?

\section{Power}

26. Did the study have sufficient power to detect a clinically important effect where the probability of a difference being due to chance is less than $5 \%$ ? 